\title{
Limitations and ceiling effects with circumferential minimally invasive correction techniques for adult scoliosis: analysis of radiological outcomes over a 7-year experience
}

\author{
Neel Anand, M.D., M.Ch.Orth., ${ }^{1}$ Eli M. Baron, M.D., ${ }^{2}$ and BabaK Khandehroo, M.D. ${ }^{1}$ \\ Departments of ${ }^{1}$ Surgery and ${ }^{2}$ Neurosurgery, Cedars-Sinai Medical Center, Los Angeles, California
}

\begin{abstract}
Object. Minimally invasive correction of adult scoliosis is a surgical method increasing in popularity. Limited data exist, however, as to how effective these methodologies are in achieving coronal plane and sagittal plane correction in addition to improving spinopelvic parameters. This study serves to quantify how much correction is possible with present circumferential minimally invasive surgical (cMIS) methods.

Methods. Ninety patients were selected from a database of 187 patients who underwent cMIS scoliosis correction. All patients had a Cobb angle greater than $15^{\circ}, 3$ or more levels fused, and availability of preoperative and postoperative 36-inch standing radiographs. The mean duration of follow-up was 37 months. Preoperative and postoperative Cobb angle, sagittal vertical axis (SVA), coronal balance, lumbar lordosis (LL), and pelvic incidence (PI) were measured. Scatter plots were performed comparing the pre- and postoperative radiological parameters to calculate ceiling effects for SVA correction, Cobb angle correction, and PI-LL mismatch correction.

Results. The mean preoperative SVA value was $60 \mathrm{~mm}$ (range $11.5-151 \mathrm{~mm}$ ); the mean postoperative value was $31 \mathrm{~mm}$ (range 0-84 mm). The maximum SVA correction achieved with cMIS techniques in any of the cases was 89 $\mathrm{mm}$. In terms of coronal Cobb angle, a mean correction of $61 \%$ was noted, with a mean preoperative value of $35.8^{\circ}$ (range $15^{\circ}-74.7^{\circ}$ ) and a mean postoperative value of $13.9^{\circ}$ (range $0^{\circ}-32.5^{\circ}$ ). A ceiling effect for Cobb angle correction was noted at $42^{\circ}$. The ability to correct the PI-LL mismatch to $10^{\circ}$ was limited to cases in which the preoperative PI-LL mismatch was $38^{\circ}$ or less.

Conclusions. Circumferential MIS techniques as currently used for the treatment of adult scoliosis have limitations in terms of their ability to achieve SVA correction and lumbar lordosis. When the preoperative SVA is greater than $100 \mathrm{~mm}$ and a substantial amount of lumbar lordosis is needed, as determined by spinopelvic parameter calculations, surgeons should consider osteotomies or other techniques that may achieve more lordosis.

(http://thejns.org/doi/abs/10.3171/2014.3.FOCUS13585)
\end{abstract}

KEY WORDS $\quad$ minimally invasive surgery $\quad \bullet \quad$ adult scoliosis $\quad \bullet$
radiographic parameters

$\mathrm{M}$ AINTENANCE of sagittal and coronal balance has been the cornerstone radiological outcomes of adult scoliosis surgery. ${ }^{12}$ While traditional open methods have been effective in achieving these outcomes, ${ }^{25}$ open methods have been historically associated with high-volume blood loss ${ }^{19,23}$ and relatively high rates of medical complications. Complications have been reported as occurring in as many as $70 \%$ of adult patients undergoing open deformity correction. ${ }^{6}$ Given this, minimally invasive methods of correction, with reduced blood loss and reduced complication rates, may be a useful alternative to open scoliosis correction in selected patients..$^{2,4}$ Questions have arisen, however, regarding the radiologi-

Abbreviations used in this paper: $\mathrm{ALIF}=$ anterior lumbar interbody fusion; AxiaLIF = Axial Lumbar Interbody Fusion; cMIS = circumferential minimally invasive surgical; $\mathrm{LL}=$ lumbar lordosis; $\mathrm{PI}=$ pelvic incidence; $\mathrm{SVA}=$ sagittal vertical axis. cal correction achieved with minimally invasive scoliosis techniques, specifically with regard to pelvic parameters and other traditionally reported radiological outcomes. ${ }^{20}$ Limited data exist regarding how effective these methods are in establishing optimal spinopelvic balance. Additionally, few studies exist regarding the maximum ability to correct coronal deformity via these techniques. This study serves to answer some of the questions as to how effective minimally invasive scoliosis surgery is for correction of sagittal plane deformity and correction of coronal plane deformity, as well as how effective it is in restoring ideal spinopelvic balance parameters.

\section{Methods}

A review of a database of 187 cases involving patients who underwent circumferential minimally invasive surgical (cMIS) treatment for thoracolumbar disorders 
N. Anand, E. M. Baron, and B. Khandehroo

TABLE 1: Data categorized by upper instrumentation level of fusion*

\begin{tabular}{lccc}
\hline \multicolumn{1}{c}{ Variable } & Lumbar (L1-2) & Lower Thoracic (T10-12) & Upper Thoracic (T3-5) \\
\hline total no. of cases & 37 & 45 & 8 \\
DLIF: mean 4 levels (range 2-7) & 33 & 43 & 4 \\
AxiaLIF: mean 1 level (range 1-2) & 15 & 24 & 1 \\
posterior pedicle screw \& rod placement: mean 6 & 37 & 45 & 2 \\
$\quad$ levels (range 3-15) & 26 & 32 & 2 \\
extension to sacrum & & & \\
\hline
\end{tabular}

* Values represent numbers of cases. DLIF = direct lateral interbody fusion.

between January 2007 and May 2012 identified 132 patients treated for adult spinal deformity (adult scoliosis). Of these 132 patients, 98 had a Cobb angle greater than $15^{\circ}$ and had 3 or more levels fused. Of these 98 patients, 90 had available preoperative and postoperative 36-inch standing radiographs including the hips and had not undergone any kind of osteotomy or facet resection. These 90 patients constitute the study group for the present study.

All patients underwent a combination of one or more minimally invasive strategies. These included a direct lateral transpsoas approach to the lumbar spine with interbody fusion. Additionally, when fusion was performed to the sacrum, transsacral Axial Lumbar Interbody Fusion (AxiaLIF) fixation was used at L5-S1. All patients also underwent minimally invasive posterior spinal fusion with percutaneous pedicle screw and rod placement, as described elsewhere. ${ }^{5}$ The minimally invasive strategies used and the levels treated are detailed in Table 1. The study group included 59 women and 31 men. Their mean age was 63.5 years (range $21-85$ years). The mean number of surgically treated levels was 6.3 (range 3-15 levels), and the mean duration of follow-up was 40 months (range 7-79 months). All patients were flexible or stiff as described by Silva and Lenke. ${ }^{22}$ No patient had a rigid fused spine.

Preoperative and postoperative Cobb angle, sagittal vertical axis (SVA), coronal balance, pelvic incidence (PI), and PI-lumbar lordosis (LL) mismatch were measured by using computerized software on 36-inch standing radiographs, using measurement definitions and methodologies as described by O'Brien et al. ${ }^{15}$

Scatter plots were created for comparison of pre- and postoperative radiological parameters.

\section{Results}

Table 2 shows preoperative and postoperative radiographic parameters. The mean preoperative SVA value was $60 \mathrm{~mm}$ (range $11.5-151 \mathrm{~mm}$ ), and the mean postoperative value was $31 \mathrm{~mm}$ ( 0 to $84 \mathrm{~mm}$ ). In general, correction of the SVA to the normal range $\left(0-50 \mathrm{~mm}^{17}\right)$ could only be achieved in patients with a preoperative SVA of $100 \mathrm{~mm}$ or less (Fig. 1). A ceiling effect for correction of the SVA was also noted (Fig. 2). The maximum SVA correction achieved with cMIS techniques in any of the cases analyzed was $89 \mathrm{~mm}$. In terms of coronal Cobb angles, a mean correction of $62 \%$ was noted; the mean preoperative value was $35.8^{\circ}$ (range $15^{\circ}-74.7^{\circ}$ ), and the mean postoperative value was $13.9^{\circ}$ (range $\left.0^{\circ}-32.5^{\circ}\right)$. A ceiling effect for Cobb angle correction was noted at $42^{\circ}$ (Fig. 3).

Ideal spinopelvic balance is established when the pelvic incidence is equal to lumbar lordosis $\pm 10^{\circ} .{ }^{17}$ Figure 4 shows preoperative PI-LL mismatch versus postoperative PI-LL mismatch. With present-day cMIS strategies the ability to correct the PI-LL mismatch to $10^{\circ}$ was limited to cases in which the preoperative PI-LL mismatch was $38^{\circ}$ or less.

In terms of clinical outcomes there was a distinct trend toward better functional outcomes when the postoperative SVA was less than $50 \mathrm{~mm}$ (Table 3). Three patients needed hardware revision surgery because of misplaced screws or hardware prominence, and 5 patients had a pseudarthrosis at L5-S1 (all 5 had AxiaLIF at that level) (Table 4).

\section{Discussion}

Over the last several years, numerous publications have reported on health-related quality of life outcomes with re-

TABLE 2: Radiological outcome*

\begin{tabular}{|c|c|c|c|c|c|c|}
\hline Measure & Preop & Last Postop & Change & $\%$ Change & Max Change & $\mathrm{p}$ Value \\
\hline Cobb angle & $35.8^{\circ}\left(15^{\circ}-74.7^{\circ}\right)$ & $13.9^{\circ}\left(0^{\circ}-32.5^{\circ}\right)$ & $22.2^{\circ}\left(3.5^{\circ}-42^{\circ}\right)$ & $61.6(16-100)$ & $42.2^{\circ}$ & $<0.01$ \\
\hline coronal balance & $32.1 \mathrm{~mm}(5.2-142.9 \mathrm{~mm})$ & $12.8 \mathrm{~mm}(0-61 \mathrm{~mm})$ & $18.8 \mathrm{~mm}(2.3-118 \mathrm{~mm})$ & $57(8.3-100)$ & & $<0.01$ \\
\hline SVA & $60 \mathrm{~mm}(11.5-151 \mathrm{~mm})$ & 31 mm (0-84 mm) & $28.8 \mathrm{~mm}(2.4-89 \mathrm{~mm})$ & $51(17-100)$ & $89 \mathrm{~mm}$ & $<0.01$ \\
\hline lumbar lordosis & $45.4^{\circ}\left(15.4^{\circ}-70.2^{\circ}\right)$ & $48.6^{\circ}\left(15.7^{\circ}-67.4^{\circ}\right)$ & & & & \\
\hline pelvic incidence & $55.3^{\circ}\left(31^{\circ}-84^{\circ}\right)$ & $56^{\circ}\left(35^{\circ}-86^{\circ}\right)$ & & & & \\
\hline PI-LL mismatch & $13.8^{\circ}\left(1^{\circ}-39.6^{\circ}\right)$ & $10.1^{\circ}\left(0.2^{\circ}-30^{\circ}\right)$ & & & $28.7^{\circ}$ & $<0.01$ \\
\hline
\end{tabular}

* Values represent mean (range) unless otherwise indicated. 


\section{Ceiling effect of circumferential MIS techniques for scoliosis}

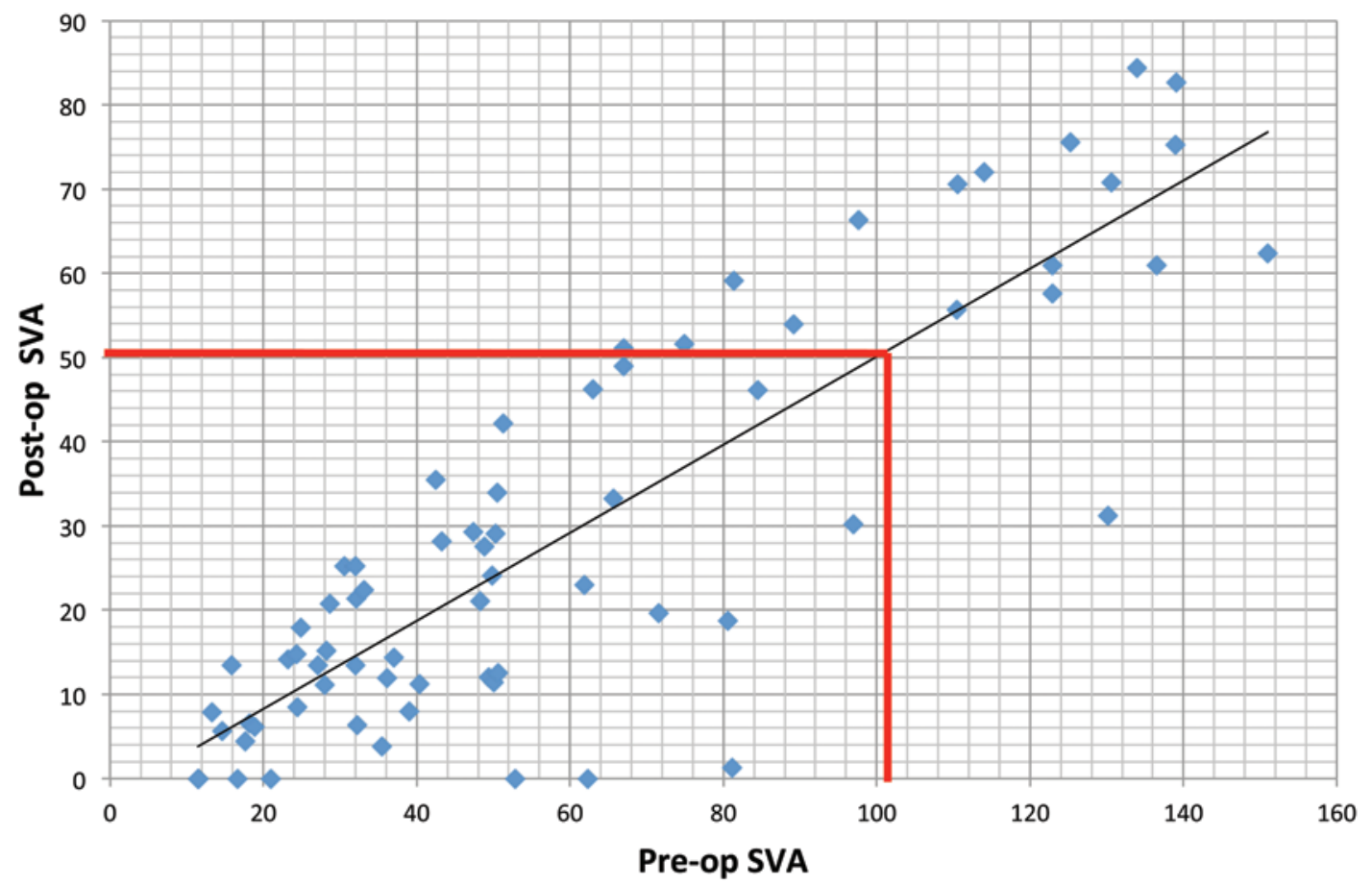

FIG. 1. Scatter plot showing preoperative versus postoperative SVA. In general, a postoperative SVA of $50 \mathrm{~mm}$ or less could only be achieved in patients with a preoperative SVA of $100 \mathrm{~mm}$ or less.

gard to minimally invasive scoliosis correction. $3,5,7,8,13,21,24$ Nevertheless, there are limited data regarding radiographic evaluation., ${ }^{3,13,21}$ Specifically, there has been an absence of analysis with respect to SVA, pelvic tilt, and the relationship between lumbar lordosis and pelvic incidence. ${ }^{20}$ Schwab et al. delineated the importance of the pelvis when considering the spine in terms of balance and alignment. ${ }^{16}$ They noted in their validation of the Scoliosis Research Society adult spinal deformity classification the impor- tance of including spinopelvic parameters such as SVA, pelvic tilt, and the relationship between pelvic incidence and lumbar lordosis expressed as pelvic incidence minus lumbar lordosis in surgical planning. ${ }^{17}$ Because abnormalities of these parameters have been shown to have a high correlation with pain and disability, they should be considered when proposing deformity correction and realignment procedures. ${ }^{14,18}$ In the Scoliosis Research Society-Schwab adult spinal deformity classification validation study, the

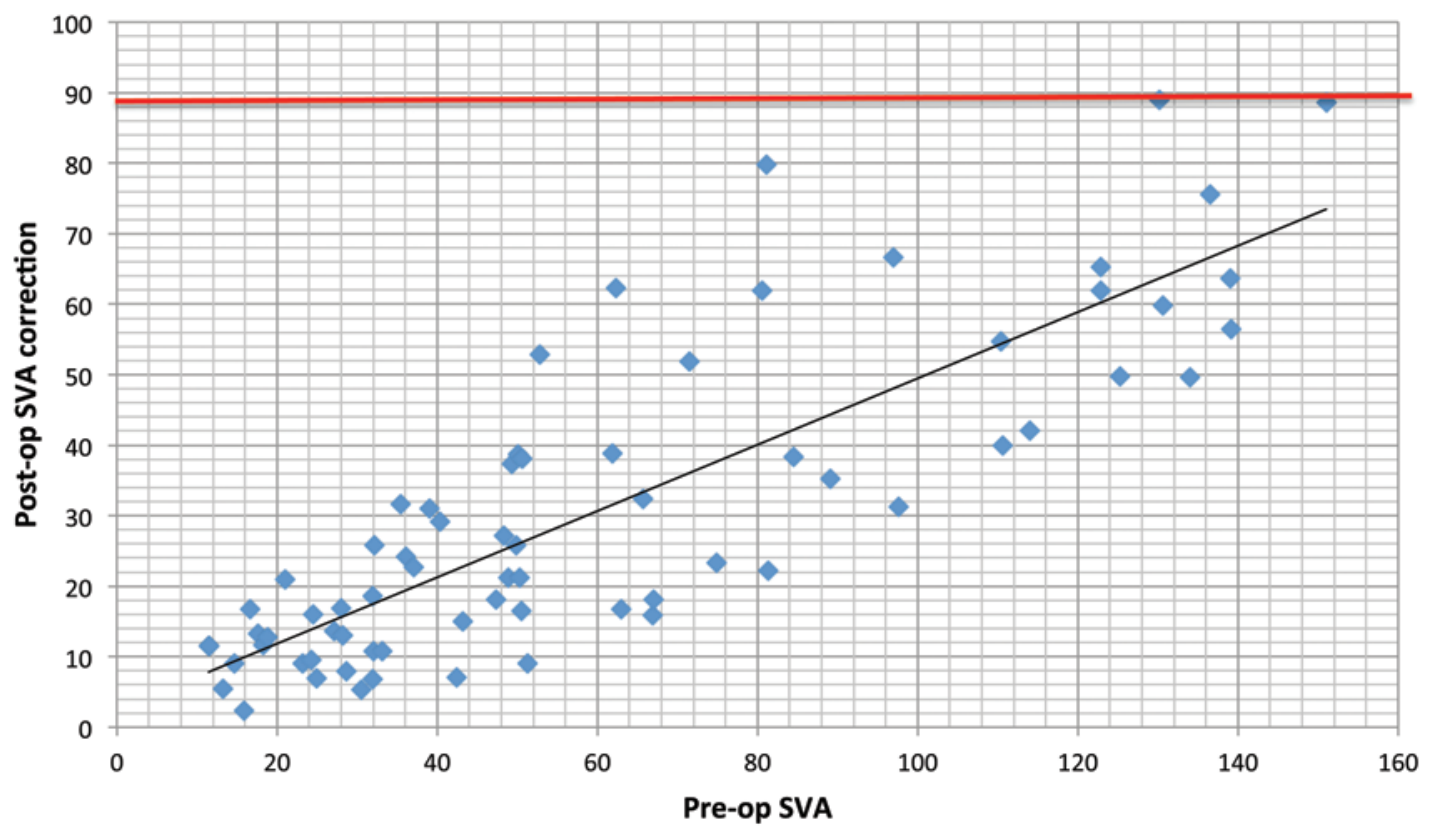

FIG. 2. Scatter plot showing preoperative SVA versus postoperative SVA correction. A ceiling effect of $89 \mathrm{~mm}$ was noted. 
N. Anand, E. M. Baron, and B. Khandehroo

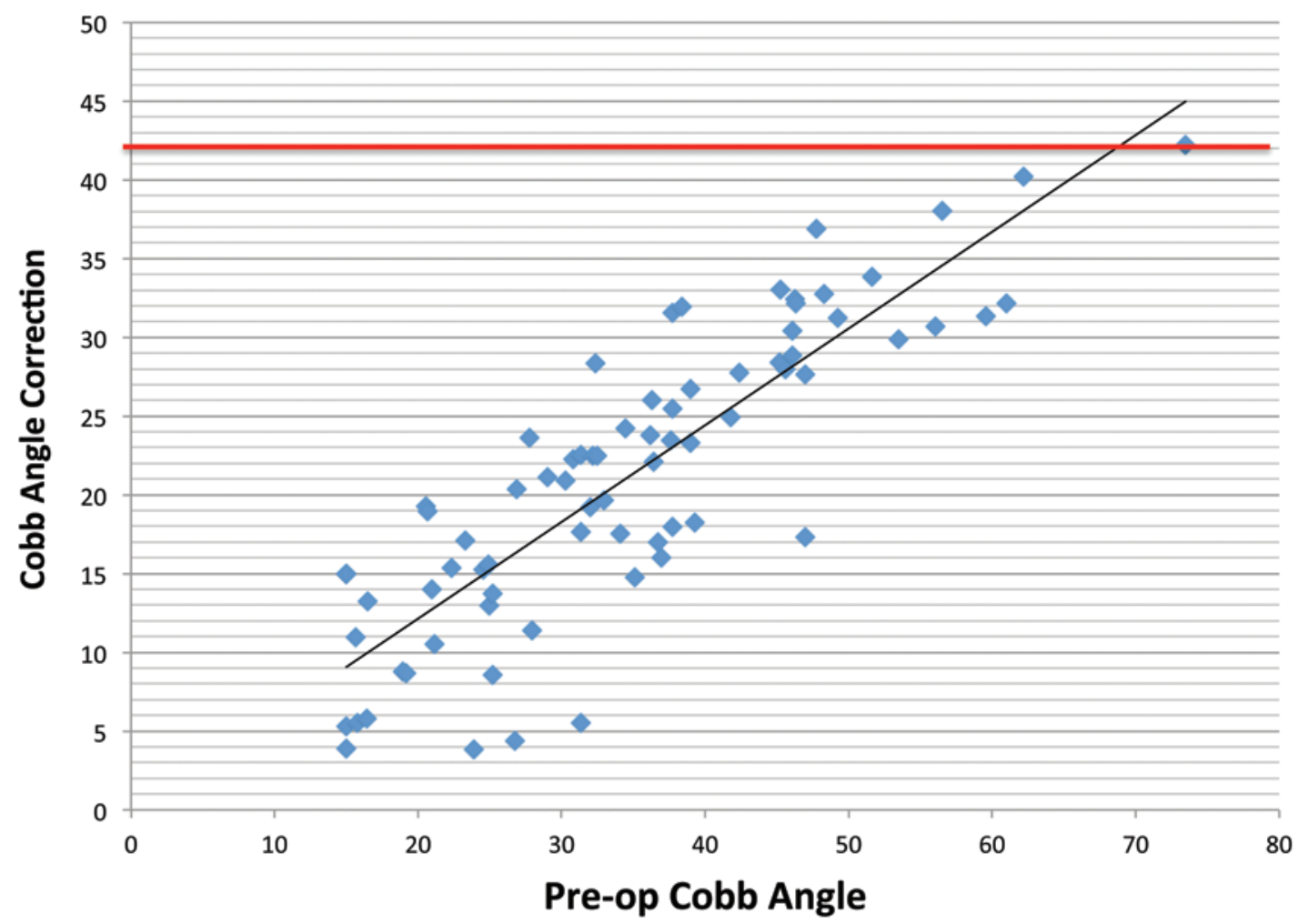

Fig. 3. Scatter plot showing preoperative Cobb angle $\left({ }^{\circ}\right)$ versus Cobb angle correction $\left(^{\circ}\right)$. A ceiling effect of $42^{\circ}$ was noted.

authors use a radiographic parameter of pelvic incidence minus lumbar lordosis within $10^{\circ}$ as their baseline sagittal modifier. Additionally, pelvic tilt of less than $20^{\circ}$ is considered optimal as is SVA of less than $4.7 \mathrm{~cm}$. These parameters set the stage in determining how much lordosis and correction to achieve during realignment procedures. ${ }^{17}$
Additionally, the coronal Cobb angle is important in the correction of adult scoliosis, although it may be a less important outcome than sagittal balance..$^{10,11}$

Yadla et al. noted major curve correction to be a mean of $26.6^{\circ}$ for 2129 patients. Additionally, average curve reduction was noted to be $40.7 \% .^{25}$ In the present study, our

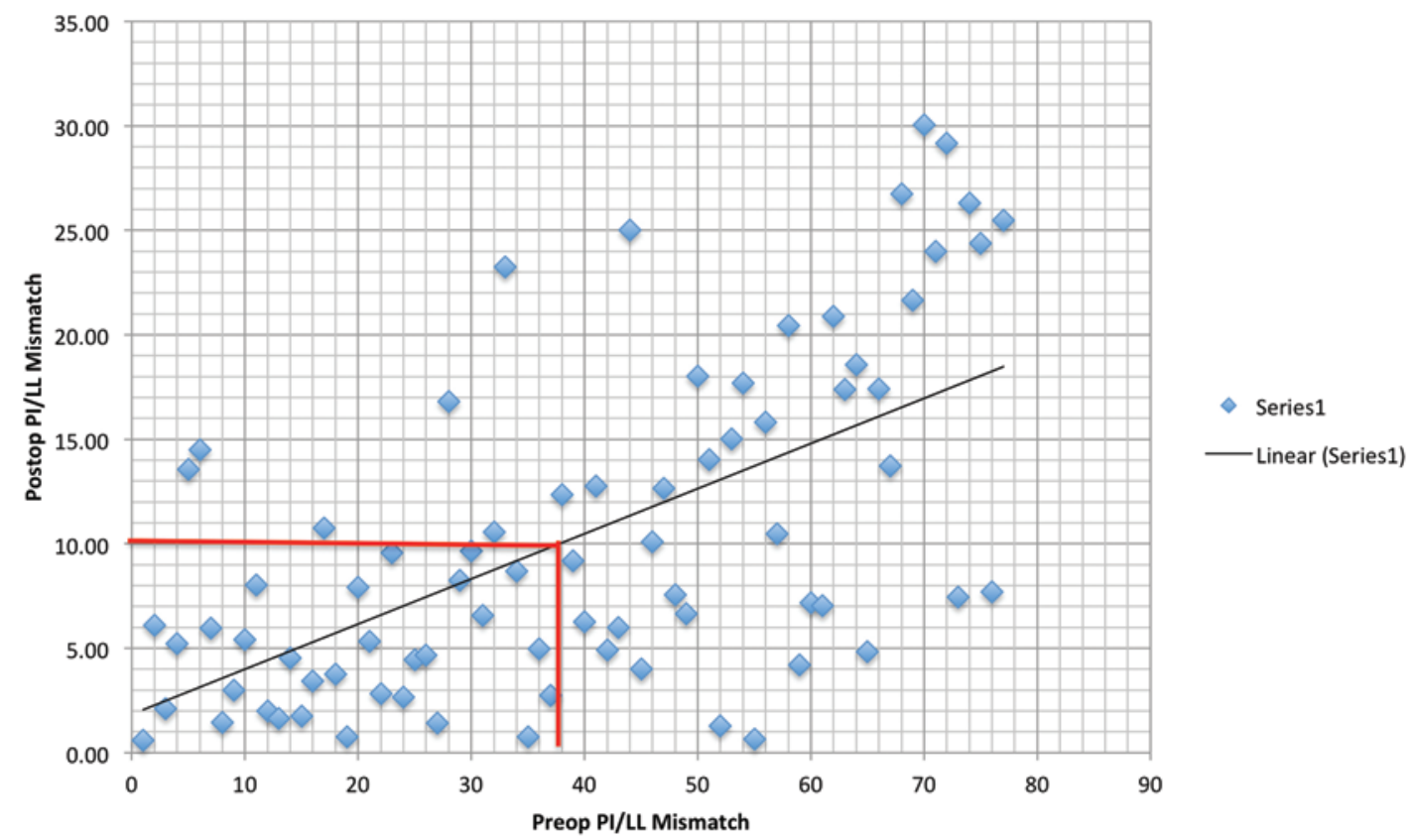

FIG. 4. Preoperative PI-LL mismatch $\left(^{\circ}\right.$ ) versus postoperative PI-LL mismatch. In general, a postoperative PI-LL mismatch of $10^{\circ}$ or less could only be achieved in patients with a preoperative PI-LL mismatch of $38^{\circ}$ or less. 


\section{Ceiling effect of circumferential MIS techniques for scoliosis}

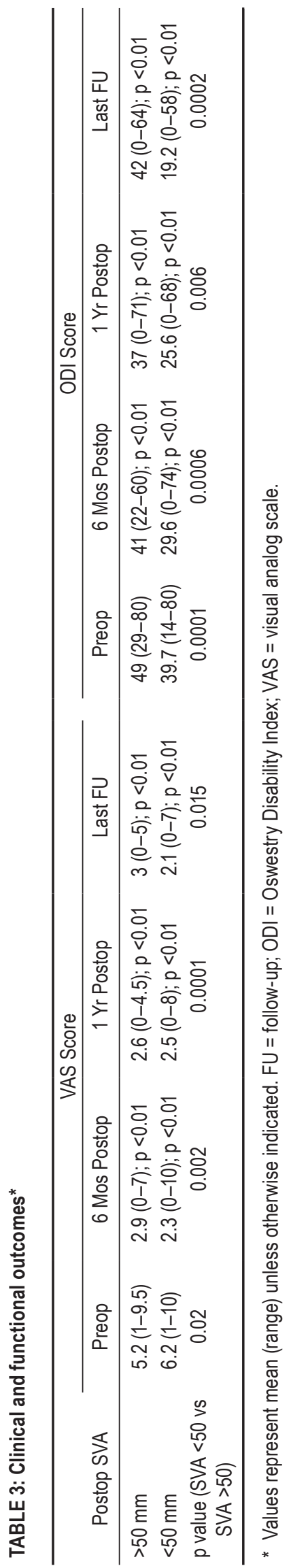

value, achieved with cMIS correction of scoliosis, was $62 \%$. Nevertheless, using cMIS techniques, we noted a ceiling effect for Cobb angle correction of $42^{\circ}$. This has implications, as curves larger than $80^{\circ}$ may not be appropriate for treatment using current cMIS strategies. Of course, our scatter plot was derived from studying curves largely between $20^{\circ}$ and $80^{\circ}$, and thus, extrapolating this for numbers beyond $70^{\circ}$ or $80^{\circ}$ may not be applicable.

Sagittal plane alignment has been noted as a critical parameter for outcomes in the setting of adult spinal deformity. ${ }^{10,11,16}$ Our data show a ceiling effect for sagittal vertical axis correction of $89 \mathrm{~mm}$. Additionally, we found that in general, in order to correct the SVA to the normal range of $50 \mathrm{~mm}$ or less with cMIS techniques, the preoperative SVA had to be $100 \mathrm{~mm}$ or less. We noted improved VAS and Oswestry Disability Index scores when the postoperative SVA was less than $50 \mathrm{~mm}$ compared with postoperative SVA greater than $50 \mathrm{~mm}$ (Table 3). The implication here is that other techniques may be necessary to achieve optimal sagittal alignment in cases of greater than $100 \mathrm{~mm}$ positive sagittal balance (Fig. 5). Other techniques such as minimally invasive anterior longitudinal ligament release, ${ }^{9}$ anterior lumbar interbody fusion (ALIF) at L5-S1, or posterior column osteotomies may afford increased lordosis, and thus, better result in correction of the SVA. In terms of achieving a postoperative pelvic incidence minus lumbar lordosis parameter within $10 \mathrm{~mm}$, we noted a PI-LL mismatch of $38^{\circ}$ on average to be the maximum value of preoperative mismatch that could be corrected using our described minimally invasive techniques. Once again, the implication is that mismatches of greater than $38^{\circ}$ to $40^{\circ}$ may require other techniques to achieve appropriate lordosis.

Some of the limitations observed in our series may be inherent to the techniques used in the lateral transpsoas approach. Acosta et al. reviewed the records of 36 patients treated with minimally invasive direct lateral interbody fusion ${ }^{1}$ and reported that it did not improve regional lumbar lordosis. On average, however, 1.8 levels were treated per patient. The authors reported that transpsoas interbody fusion improved segmental regional and global coronal plane alignment. They noted, however, that regional lordosis and global sagittal alignment were not improved by these techniques. Similar, Sharma et al. noted a mean gain of $2.8^{\circ}$ in lordosis at each level treated this way, but no significant change in the overall coronal or sagittal alignment. ${ }^{21}$ Johnson et al. reported pelvic parameters and sagittal balance in patients undergoing these techniques for lumbar degenerative conditions. ${ }^{13}$ There were heterogeneous methods of fixation used in their series; 6 patients underwent posterior supplemental fixation, and 3 underwent intraspinous process device fixation. The authors thought that the lateral transpsoas interbody fusion did not affect lordosis, but noted the Cobb angle in the anterior-posterior plane to be significantly reduced. These studies, however, typically involve use of the lateral transpsoas approach for short-segment deformity correction. Additionally, with these studies, anterior column placement of the interbody device to maximize lordosis, rod contouring, and deformity reduction techniques were not emphasized. 
TABLE 4: Pseudarthrosis and revision strategy

\begin{tabular}{lll}
\hline \multicolumn{1}{c}{ Description } & Value & \multicolumn{1}{c}{ Intervention } \\
\hline no. of cases of pseudarthrosis at L5-S1* & 5 & revision anterior-posterior fusion \&/or extension to pelvis \\
no. of cases of pseudarthrosis above L5-S1 & 2 & posterior reinstrumentation \& fusion \\
total no. of pseudarthrosis (\%) & $7(7.78)$ & \\
total no. of patients w/ pseudarthrosis (\%) & $7(7.78)$ & \\
\hline
\end{tabular}

* An AxiaLIF procedure had been performed in all of these cases.

Transpsoas techniques have continued to evolve. At the start of these studies, interbody devices typically had about a $6^{\circ}$ maximum lordosis. Now there are hyperlordotic cages, such as $12^{\circ}$ and $15^{\circ}$ devices, available. These may allow surgical creation of more lordosis. Finally, recent techniques involving an anterior longitudinal ligament release may allow for even more lordosis creation. ${ }^{9}$

The use of the transsacral AxiaLIF technique may also have limited our ability to gain maximal lordosis at L5-S1, especially in patients with significant positive sagittal balance. We traditionally have used the AxiaLIF for interbody fixation rather than to achieve lordosis. When lordosis is desired at L5-S1 to correct sagittal parameters, a lordotic ALIF device may be desirable and has been our preference over the last 2 years.
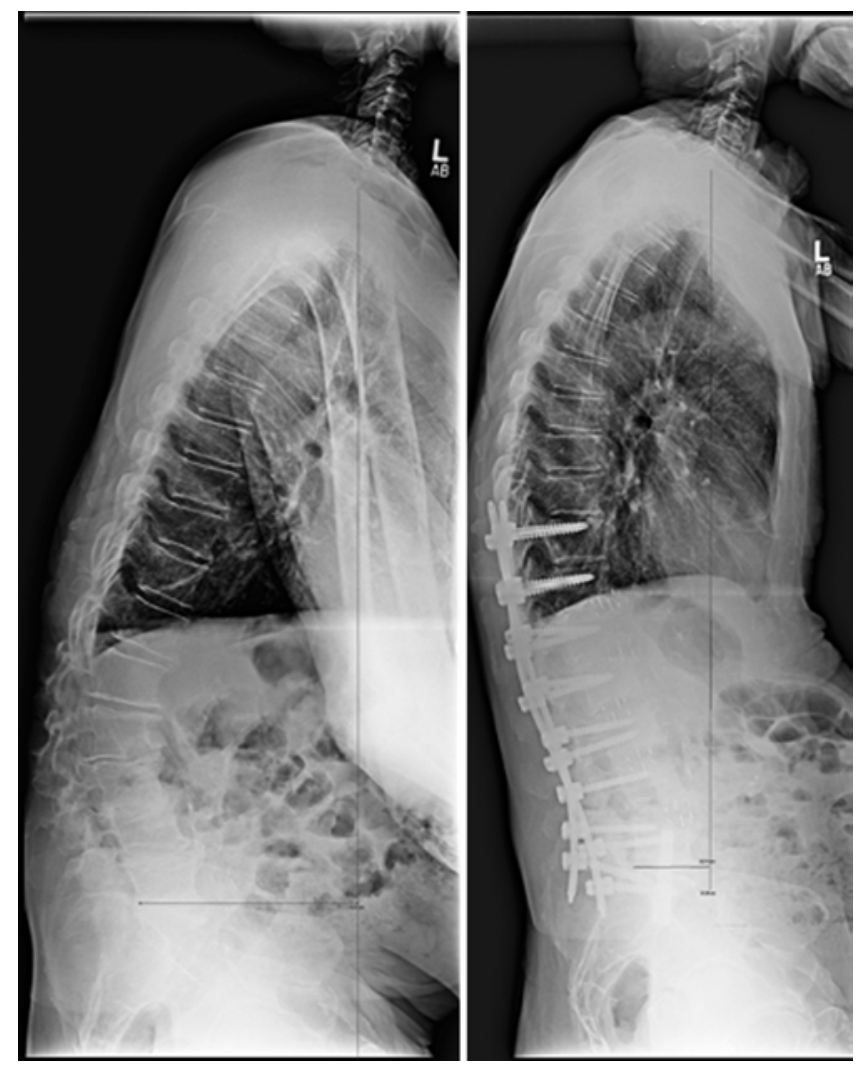

FIG. 5. Preoperative (left) and postoperative (right) lateral 36 -inch radiographs obtained in an 80 -year-old male patient with degenerative scoliosis, thoracolumbar kyphosis, and severe back and leg pain refractory to conservative measures. He underwent cMIS correction from T-11 to S-1. His SVA was $143 \mathrm{~mm}$ preoperatively and $53.74 \mathrm{~mm}$ postoperatively.

\section{Conclusions}

Circumferential minimally invasive scoliosis treatment techniques as currently used have limitations in terms of their ability to achieve SVA correction and lumbar lordosis. When the preoperative SVA is greater than $100 \mathrm{~mm}$ and a substantial amount of lumbar lordosis is needed, as determined by using spinopelvic parameter calculations, surgeons should consider osteotomies or other techniques that may achieve more lordosis.

The release of the anterior longitudinal ligament in direct lateral minimally invasive techniques may allow for even more substantial correction at each level treated this way. Similarly, hyperlordotic cages with appropriate anterior column positioning may allow for increased lordosis using the standard technique. Future directions may entail a combination of hyperlordotic ALIF cages at L5-S1, newer minimally invasive direct lateral techniques, and, when extreme correction is needed, a hybrid procedure involving posterior column osteotomies in addition to minimally invasive direct lateral techniques. We have applied protocols over the last 2 years and they are the subject of a future study.

Spinopelvic parameters are critical in the formulation of a surgical plan for the treatment of adult scoliosis. When a scoliotic curve is addressed using minimally invasive techniques, appropriate planning is essential, and a judicious use of minimally invasive strategies should be undertaken depending on the degree of deformity present.

\section{Disclosure}

Dr. Anand reports a consultant relationship with Medtronic and Baxano Surgical; direct stock ownership in Medtronic and Globus Medical; and receipt of royalties from Medtronic, Globus Medical, Baxano Surgical, and NuVasive.

Author contributions to the study and manuscript preparation include the following. Conception and design: Anand, Baron. Acquisition of data: Anand, Khandehroo. Analysis and interpretation of data: Anand. Drafting the article: Baron. Critically revising the article: Anand, Baron. Statistical analysis: Khandehroo.

\section{References}

1. Acosta FL, Liu J, Slimack N, Moller D, Fessler R, Koski T: Changes in coronal and sagittal plane alignment following minimally invasive direct lateral interbody fusion for the treatment of degenerative lumbar disease in adults: a radiographic study. Clinical article. J Neurosurg Spine 15:92-96, 2011

2. Anand N, Baron EM: Minimally invasive approaches for the correction of adult spinal deformity. Eur Spine J 22 Suppl 2: S232-S241, 2013

3. Anand N, Baron EM, Khandehroo B: Does minimally inva- 


\section{Ceiling effect of circumferential MIS techniques for scoliosis}

sive transsacral fixation provide anterior column support in adult scoliosis? Clin Orthop Relat Res [epub ahead of print], 2013

4. Anand N, Baron EM, Khandehroo B, Kahwaty S: Long-term 2- to 5-year clinical and functional outcomes of minimally invasive surgery for adult scoliosis. Spine (Phila Pa 1976) 38: $1566-1575,2013$

5. Anand N, Rosemann R, Khalsa B, Baron EM: Mid-term to long-term clinical and functional outcomes of minimally invasive correction and fusion for adults with scoliosis. Neurosurg Focus 28(3):E6, 2010

6. Baron EM, Albert TJ: Medical complications of surgical treatment of adult spinal deformity and how to avoid them. Spine (Phila Pa 1976) 31 (19 Suppl):S106-S118, 2006

7. Caputo AM, Michael KW, Chapman TM, Jennings JM, Hubbard EW, Isaacs RE, et al: Extreme lateral interbody fusion for the treatment of adult degenerative scoliosis. J Clin Neurosci 20:1558-1563, 2013

8. Caputo AM, Michael KW, Chapman TM Jr, Massey GM, Howes CR, Isaacs RE, et al: Clinical outcomes of extreme lateral interbody fusion in the treatment of adult degenerative scoliosis. ScientificWorldJournal 2012:680643, 2012

9. Deukmedjian AR, Dakwar E, Ahmadian A, Smith DA, Uribe JS: Early outcomes of minimally invasive anterior longitudinal ligament release for correction of sagittal imbalance in patients with adult spinal deformity. ScientificWorldJournal 2012:789698, 2012

10. Glassman SD, Berven S, Bridwell K, Horton W, Dimar JR: Correlation of radiographic parameters and clinical symptoms in adult scoliosis. Spine (Phila Pa 1976) 30:682-688, 2005

11. Glassman SD, Bridwell K, Dimar JR, Horton W, Berven S, Schwab F: The impact of positive sagittal balance in adult spinal deformity. Spine (Phila Pa 1976) 30:2024-2029, 2005

12. Heary RF: Evaluation and treatment of adult spinal deformity. J Neurosurg Spine 1:9-18, 2004

13. Johnson RD, Valore A, Villaminar A, Comisso M, Balsano M: Pelvic parameters of sagittal balance in extreme lateral interbody fusion for degenerative lumbar disc disease. J Clin Neurosci 20:576-581, 2013

14. Lafage V, Schwab F, Patel A, Hawkinson N, Farcy JP: Pelvic tilt and truncal inclination: two key radiographic parameters in the setting of adults with spinal deformity. Spine (Phila Pa 1976) 34:E599-E606, 2009

15. O’Brien MF, Kuklo TR, Blanke K, Lenke LG (eds): Spinal Deformity Study Group Radiographic Measurement Manual. Memphis, TN: Medtronic Sofamor Danek, 2005
16. Schwab F, Lafage V, Patel A, Farcy JP: Sagittal plane considerations and the pelvis in the adult patient. Spine (Phila Pa 1976) 34:1828-1833, 2009

17. Schwab F, Ungar B, Blondel B, Buchowski J, Coe J, Deinlein $D$, et al: Scoliosis Research Society-Schwab adult spinal deformity classification: a validation study. Spine (Phila Pa 1976) 37:1077-1082, 2012

18. Schwab FJ, Blondel B, Bess S, Hostin R, Shaffrey CI, Smith JS, et al: Radiographical spinopelvic parameters and disability in the setting of adult spinal deformity: a prospective multicenter analysis. Spine (Phila Pa 1976) 38:E803-E812, 2013

19. Seo HJ, Kim HJ, Ro YJ, Yang HS: Non-neurologic complications following surgery for scoliosis. Korean J Anesthesiol 64:40-46, 2013

20. Shaffrey CI, Smith JS: Editorial. Minimally invasive spinal deformity surgery. J Neurosurg Spine 18:1-3, 2013

21. Sharma AK, Kepler CK, Girardi FP, Cammisa FP, Huang RC, Sama AA: Lateral lumbar interbody fusion: clinical and radiographic outcomes at 1 year: a preliminary report. J Spinal Disord Tech 24:242-250, 2011

22. Silva FE, Lenke LG: Adult degenerative scoliosis: evaluation and management. Neurosurg Focus 28(3):E1, 2010

23. Transfeldt EE, Topp R, Mehbod AA, Winter RB: Surgical outcomes of decompression, decompression with limited fusion, and decompression with full curve fusion for degenerative scoliosis with radiculopathy. Spine (Phila Pa 1976) 35:1872-1875, 2010

24. Wang MY, Mummaneni PV: Minimally invasive surgery for thoracolumbar spinal deformity: initial clinical experience with clinical and radiographic outcomes. Neurosurg Focus 28(3):E9, 2010

25. Yadla S, Maltenfort MG, Ratliff JK, Harrop JS: Adult scoliosis surgery outcomes: a systematic review. Neurosurg Focus 28(3):E3, 2010

Manuscript submitted December 30, 2013.

Accepted March 20, 2014.

Please include this information when citing this paper: DOI: 10.3171/2014.3.FOCUS13585.

Address correspondence to: Neel Anand, M.D., M.Ch.Orth., Cedars-Sinai Medical Center, 444 S. San Vicente Blvd., Ste. 800, Los Angeles, CA 90048. email: anandn@cshs.org. 